\title{
Urdimento
}

\section{OS SERES FICCIONAIS: IDENTIDADE E ALTERIDADE - EXPLORAÇÃO-DISSECAÇÃO-INVENÇÃO DE MATERIAIS DE ATUAÇÃO}

\author{
Matteo Bonfitto ${ }^{1}$
}

\section{Resumo}

O presente artigo busca examinar algumas conexões existentes entre os seres ficcionais e as tensões entre identidade e alteridade. Para esse fim, diversas referências são utilizadas, desde estudos teóricos até experiências práticas vivenciadas em primeira pessoa.

Palavras-chave: atuação, identidade, alteridade.

\begin{abstract}
This article tries to examine some existent connections between fictional beings, identity and alterity. In order to do so, different references are used, from theoretical studies to first-hand practical experiences.
\end{abstract}

Keywords: acting, identity, alterity.

Semelhante às oscilações e flutuações que podem permear a dinâmica do olhar, que se forma a partir da combinação muitas vezes instável, entre percepção e cognição, o presente artigo envolverá, ao mesmo tempo, a descrição de um seminário teórico-prático ministrado no Centro de Artes (CEART) da Universidade do Estado de Santa Catarina (UDESC) no primeiro semestre de 2009, elaborações geradas por outras, análogas experiências, e percepções que emergirão do ato de escrever, que possibilitará, espero, uma revisão do supostamente já sabido.

O referido seminário deveria relacionar a produção de seres ficcionais com as tensões entre identidade e alteridade. A fim de tentar materializar a consistência que permeou tal evento, percorrerei alguns fatos e elaborações que serviram como suporte poético e conceitual nesse caso. Pois bem, comecemos então pelos seres ficcionais.

\section{Dos seres ficcionais à exploração de materiais}

Em Pavis, por exemplo, nos deparamos com uma reflexão que tenta abarcar as transformações históricas da assim chamada 'personagem', das máscaras gregas até o seu funcionamento enquanto actante produtor de Março 2009 - № 12

Os seres ficcionais: identidade e alteridade... Matteo Bonfitto
${ }^{1}$ Matteo Bonfitto é ator, diretor, e pesquisador teatral. Formado pela Escola de Arte Dramática da USP, pelo DAMS (Departamento de Arte, Música e Espetáculo) da Universidade de Bologna, Itália (graduação), pela Escola de Comunicações e Artes ECA - USP (mestrado), e pela Royal Holloway University of London (doutorado). Além de vários artigos sobre o trabalho do ator, publicou 0 Ator Compositor (Perspectiva, 2002), A Cinética do Invisível. Processos de Atuação no Teatro de Peter Brook (Perspectiva, 2009), e é um dos autores de O Pós-Dramático (Perspectiva, 2009). Leciona atualmente no Depto de Artes Cênicas

da Universidade Estadual de Campinas (UNICAMP). 


\section{Urdimento}

${ }^{2}$ Ver PAVIS, Patrice; verbete 'Personagem', in Dicionário de Teatro. São Paulo: Perspectiva, 2007, pp. 285-289.

${ }^{3}$ BONFITTO, Matteo. 0 Ator Compositor. São Paulo: Perspectiva, 2002.

${ }^{4}$ Ver BONFITTO, obra citada, pp. 127-137. signos, passando por sua individualização na dramaturgia burguesa, por sua tipificação na Commedia Dell'Arte, por sua dissolução nos dramas simbolistas, pela desmontagem da personagem em Brecht, pelo seu recentramento no surrealismo, etc... . ${ }^{2}$ Dessa forma, o estudioso francês aborda a personagem em sua dimensão semântica assim como em sua dimensão semiótica. Sem pretender desconsiderar ou minimizar a importância de tal abordagem, creio, como pesquisador e como artista, que há outros modos de apreensão dos seres ficcionais que podem gerar estímulos consistentes em termos criativos.

Em $O$ Ator Compositor, ${ }^{3}$ proponho, a partir da noção de actante - tudo aquilo que age, atua - a diferenciação entre três categorias de seres ficcionais. A utilização do termo 'seres ficcionais' nesse caso não é absolutamente casual. Tal escolha pretende atingir um horizonte mais amplo do que aquele associado ao termo 'personagem', frequentemente relacionado a indivíduos ou tipos humanos. De fato, quando pensamos em seres ficcionais, podemos considerar a possibilidade de lidar com 'seres' que não são simplesmente indivíduos ou tipos, mas também com criações-composições poéticas que são funcionais às estruturas narrativas produzidas em cada processo criativo. Bastaria escolher como referência, por exemplo, fragmentos de textos dramatúrgicos produzidos pelo dadaísmo, surrealismo ou pelo expressionismo para constatar tal fato. Ou poderíamos ainda considerar exemplos extraídos de uma grande variedade de manifestações cênicas contemporâneas, do teatro experimental ao teatro-dança e à performance. Foi o contato com tais manifestações, somado às experiências vividas como ator que propiciaram a elaboração das categorias mencionadas acima, nomeadas, respectivamente, actante-máscara, actanteestado, e actante-texto. ${ }^{4}$

Seguindo tal elaboração, o actante-máscara envolve o que podemos chamar de personagem-indivíduo e personagem-tipo, as quais têm como característica o fato de serem referencializadas e temporalizadas. Ou seja, tais personagens são claramente situadas e oferecem parâmetros contextuais, psicológicos e sociológicos de reconhecimento. Na medida em que tais seres ficcionais sofrem processos de modalização, passando assim a serem definidos não somente a partir do que eles 'fazem', mas também a partir do que 'querem fazer', 'podem fazer', 'sabem fazer' e 'devem fazer', eles podem ser destemporalizados e ter, assim, a própria funcionalidade comprometida. O actante-estado, segunda categoria referida acima, seria um produto de tais processos. Já o actante-texto emergiria de modalizações ainda mais acentuadas, que podem provocar o desaparecimento da intriga e a transferência para o texto dos predicados que contribuem para a constituição da personagem enquanto sujeito. As manifestações cênicas contemporâneas, assim como a dramaturgia produzida nas últimas décadas oferecem inúmeros exemplos de actantes-estado e actantes-texto. Enquanto 


\section{Urdimento}

Uma Noite Antes da Floresta (La Nuit Juste Avant Les Forêts) de BernardMarie Koltès pode ser vista como uma obra que tem como eixo um actanteestado, Auto-Acusação (Self-Accusation) de Peter Handke contém aspectos que estão relacionados ao actante-texto.

As elaborações descritas acima foram mais tarde desdobradas e ampliadas. Entre 2002 e 2006, graças a uma bolsa concedida pela CAPES, puder viver experiências criativas com três atores de Peter Brook - Yoshi Oida, Sotigui Kouyaté e Tapa Sudana. Foi através do contato direto com as abordagens desenvolvidas por esses atores sobre a Storytelling (Arte de Contar Histórias) que a ampliação mencionada acima se deu. Longe de ser uma forma expressiva restrita ao universo infantil, as explorações da storytelling feitas por eles e por Brook envolvem práticas interculturais que geram possibilidades de criação de seres ficcionais, as quais representam uma ampliação do horizonte criativo presente no assim chamado Ocidente, onde ainda prevalece de maneira consistente as abordagens construídas por Stanislavski, Brecht, Artaud, Grotowski e Barba.

As práticas desenvolvidas por Brook e seus atores associam de maneira intrínseca os seres ficcionais aos materiais de atuação. Tal associação busca materializar, por sua vez, de diversos modos e em vários níveis - experiências - e nesse sentido pode-se reconhecer uma analogia entre as práticas desenvolvidas no $\mathrm{CICT}^{5}$ e qualidades apontadas, por exemplo, por Walter Benjamin em $O$ Narrador. ${ }^{6}$ Independentemente das especificidades históricas e contextuais, a produção de experiências representa o elo que une esse escrito de Benjamin e as explorações da storytelling, tal como desenvolvida pelo diretor inglês e seus atores. No caso de Brook e de seus atores, no entanto, a experiência não é examinada a partir de seus resultados expressivos, mas sim como um objetivo que deve ser gradualmente perseguido de maneira específica em cada processo criativo, e que emerge da ligação entre os seres ficcionais e os materiais de atuação. A fim de desdobrar a reflexão em curso, examinemos agora alguns aspectos envolvidos nessa ligação para em seguida tecer algumas considerações sobre a experiência.

Em Brook os seres ficcionais têm um caráter absolutamente processual e tal fato abre espaço para um campo aberto de exploração de materiais. Em $O$ Ator Compositor reconheço a importância dos materiais e nesse sentido proponho uma diferenciação entre material primário (corpo), material secundário (ação física) e materiais terciários (elementos constitutivos da ação física). ${ }^{7}$ Os materiais terciários envolvem tanto aspectos do aparato psicofísico do ator (memória, imaginação, etc...) quanto estímulos que podem ser utilizados no processos criativo, tal como imagens, textos, objetos, sonoridades, etc... . Os modos de exploração e de articulação de tais
${ }^{5} \mathrm{CICT}$ (Centre Internacional de Création Théâtrale) é o nome dado ao centro de pesquisas teatrais dirigido por

Brook em Paris desde 1974.

${ }^{6}$ BENJAMIN, Walter; 'O Narrador. Considerações sobre a obra de Nikolai Leskov', in Magia e Técnica, Arte e Política: ensaios sobre literatura e história da cultura. São Paulo: Brasiliense, 1994, pp. 197-221.

7Ver BONFITTO, obra citada, pp. 1-20. 


\section{Urdimento}

${ }^{8}$ Descrevo a exploração de materiais, tal como desenvolvida por Brook e seus atores, em $A$ Cinética do Invisível. Processos de Atuação no Teatro de Peter Brook, 2009. materiais constituem o modus operandi do ator. Desse modo, as experiências com os atores de Brook geraram uma ampliação de possibilidades, na medida em que revelaram diferentes percursos de articulação desses materiais.

Considerando os limites deste ensaio, não cabe aqui uma descrição detalhada de tais processos. De qualquer forma, pode-se dizer que os modos de exploração dos materiais colocados em prática pelos atores de Brook atravessam um percurso constituído por várias etapas, dentre elas a de 'ruptura', 're-composição', e 'naturalização de materiais's . A ampliação referida acima está relacionada sobretudo às múltiplas funções que os materiais podem exercer na criação de seres ficcionais. A percepção dessas múltiplas funções fez com que eu reconhecesse em termos práticos que os materiais de atuação - me refiro aqui aos materiais terciários e mais especificamente aos estímulos utilizados durante os processos criativos - não têm necessariamente um valor em si, mas podem ser desdobrados, dissecados, re-significados, inventados, a partir das abordagens, a partir dos olhares que são lançados sobre eles, a partir da atitude que temos ao 'escavar' tais materiais. E aqui chegamos na tensão entre identidade e alteridade.

\section{A construção de experiências: identidade e alteridade}

Tomemos como exemplo um bastão. Posso explorar esse material fazendo com que ele adquira diferentes significados. Ou seja, posso resignificá-lo fazendo com que ele se 'transforme' em uma espada, em uma caneta, em um varal, um cavalo, etc... . Mas, ao mesmo tempo, posso fazer com que ele seja um elemento que me faça assumir posturas inusitadas, que me faça experienciar tensões não-familiares, e assim, me faça perceber possibilidades expressivas antes desconhecidas. Tais processos foram vivenciados em um workshop dirigido pelo ator balinês Tapa Sudana, que será brevemente descrito a seguir.

Os bastões, nessa ocasião, eram utilizados em determinados momentos como objetos vazios, e podiam, assim, ser continuamente transformados. De qualquer maneira, um outro tipo de exploração foi crescentemente desenvolvida durante esse processo. Inicialmente o trabalho com o bastão gerou muitas dificuldades, uma vez que nós, os participantes, deveríamos repetir seqüências fixas de movimentos. Além de funcionarem como mediadores entre o corpo e o espaço, nesse caso uma sala de ensaios, os bastões agiram como 'mestres', tal como referido por Sudana. Em outras palavras, os bastões representaram um meio através do qual o indivíduo pode crescer fisicamente, espiritualmente, e intelectualmente. De fato, corpo, emoção e pensamento constituem o 'TRI BUANA' ('três mundos') conceito explorado por Sudana em seu trabalho como ator.

Os seres ficcionais: identidade e alteridade... Matteo Bonfitto

Março $2009-\mathrm{N}^{0} 12$ 
Conforme as sequências de movimentos eram praticadas, diferentes níveis de dificuldade emergiram. Dessa forma, o bastão se tornou progressivamente um catalisador de processos psicofísicos, através dos quais a correlação entre respiração, postura e tensão muscular pode gerar diferentes níveis de conexão entre processos interiores e exteriores. Movimentos executados com o bastão produziram gradualmente tensões musculares específicas e geraram a necessidade de explorar diferentes modos de respiração. Sudana frequentemente chamou a nossa atenção para a percepção dos impulsos e para o respeito que deveríamos demonstrar ao trabalhar com o bastão. Mais do que executar desenhos de movimentos, nós éramos estimulados a dirigir nossa atenção para as tensões existentes entre processos interiores e exteriores. Sudana nos pediu para não buscarmos 'executar ações' com o bastão. Nós deveríamos aprender, a partir do contato com o bastão, a não guiá-lo, a não impor a nossa vontade. Mas ao mesmo tempo nós deveríamos cultivar uma atitude ativa. Com o passar dos dias notei que o bastão estava me levando a assumir posturas não familiares, as quais eu não imaginava que fosse capaz de executar. Aos poucos, comecei a perceber a diferença entre 'guiar' e 'ser guiado', entre o conduzir um processo voluntariamente e o fazer com que a condução seja um catalisador de vários estímulos que podem ocorrer simultaneamente. Além disso, os bastões eram utilizados durante as nossas conversas em grupo. Nesses casos, eles eram deixados sobre o chão em frente a cada membro do grupo, apontando para o centro do círculo. Sudana nessas ocasiões nos pedia para não olharmos para a pessoa que estava falando, mas para o centro do círculo, para onde todos os bastões convergiam.

Os bastões, portanto, exerceram múltiplas funções durante a experiência guiada por Sudana. Além de funcionar como um 'objeto vazio' e como um instrumento utilizado para trabalhar fisicamente, ele foi explorado a fim de expandir as potencialidades expressivas dos atores, processo este que envolveu por sua vez a produção de experiências cinéticas e o desenvolvimento da auto-consciência. Auto-consciência aqui não diz respeito somente às ocorrências individuais subjetivas mas também à interação dinâmica entre o indivíduo e estímulos sócio-culturais e/ou ambientais. Além disso, a relação entre o ator e o bastão gerou implicações associadas com processos de individuação, de acordo com as quais o indivíduo pode ampliar as próprias referências intelectuais e afetivas.

Baseado em tais considerações, é possível perceber que a exploração de materiais, nesse caso o bastão, pode representar um elemento que catalisa a tensão entre as dimensões de identidade e de alteridade. De fato, o bastão é aqui considerado como um 'mestre', como Outro que, sendo Outro, desencadeia uma revisão do Eu em muitos níveis, e é exatamente nesse ponto que podemos retomar a reflexão sobre a experiência. 


\section{Urdimento}

${ }^{9}$ BONDÍA, Jorge Larossa; Notas Sobre a Experiência e o Saber de Experiência, em Revista Brasileira de Educação, $n^{\circ}$ 19, pp. 20-28, Jan/ Fev/Mar/Abr 2002. Disponível em http://www. anped.org.br/rbe/ rbedigital/RBDE19/ RBDE19 04 JORGE LARROSA B BŌNDIA.pdf Acesso em 02/07/2009, 18:30.
Muitas são as abordagens possíveis sobre a experiência, conceito esse que permeia o pensamento de muitos estudiosos. Nesse ensaio utilizaremos alguns aspectos colocados nesse âmbito por Jorge Larossa Bondía. O pesquisador espanhol, ao falar sobre experiência, a coloca como "tudo aquilo que nos passa", "nos acontece". Desse modo, reconhece alguns fatores que podem funcionar como obstáculos da experiência, tais como o excesso de informação, o excesso de opinião, de trabalho, e a falta de tempo. A experiência, segundo ele,

\section{[...] requer um gesto de interrupção [...] requer parar para} pensar, parar para olhar, parar para escutar, pensar mais devagar, olhar mais devagar, e escutar mais devagar; parar para sentir, sentir mais devagar, demorar-se nos detalhes, suspender a opinião, suspender o juízo, suspender a vontade, suspender o automatismo da ação, cultivar a atenção e a delicadeza, abrir os olhos e os ouvidos, falar sobre o que nos acontece, aprender a lentidão, escutar aos outros, cultivar a arte do encontro, calar muito, ter paciência e dar-se tempo e espaço. ${ }^{9}$

Se refletirmos sobre o processo de trabalho descrito com os bastões, podemos fazer uma conexão direta com os aspectos apontados por Bondía. No trabalho dos atores de Brook, podemos transpor a exploração dos bastões para uma grande variedade de materiais, mas o que é importante perceber nesse ponto é a relação existente entre tal exploração, a criação de seres ficcionais e a noção de experiência apontada acima. O trabalho com os bastões, sendo gerador de experiência que se dá a partir da tensão entre identidade e alteridade, representa uma fonte de estímulos que pode ser geradora de qualidades que contribuirão para a criação de seres ficcionais em muitos níveis. A percepção de tensões musculares não-familiares, o assumir posturas inusitadas, etc..., podem fornecer muitos elementos nesse sentido. Cabe ressaltar, por fim, que os seres ficcionais no trabalho de Brook não são resultantes de uma projeção da identidade do ator, mas sim de processos de tensão entre identidade e alteridade, os quais geram uma transformação, uma ampliação do horizonte perceptivo do ator. Os seres ficcionais, portanto, são resultantes de experiências, tal como apontado por Bondía.

Assim, esses foram alguns dos pressupostos que nortearam a proposta de trabalho com os estudantes do CEART. Como teríamos um tempo restrito, somente três encontros, propus que partíssemos de alguns materiais. Em função de tais limitações, achei que poderia ser mais adequado não propor, por exemplo, o trabalho com os bastões, que requer um tempo bem maior de execução. Partimos, então, de textos não-dramáticos (Manoel de Barros, Guimarães Rosa, Machado de Assis), de imagens (Francis Bacon), e de 
experiências pessoais. Após uma breve experimentação de algumas práticas (exploração do espaço, do contato com o outro, ações vocais, etc...), iniciamos e exploração dos referidos materiais. Atuando como um dramaturg, percorri os grupos fornecendo alguns estímulos, perguntas e provocações. Ou seja, não houve uma interferência direta na exploração cênica dos materiais, mas na atitude, no olhar através do qual eles poderiam ser explorados, escavados.

O trabalho prático foi acompanhado de discussões de textos e do exame de alguns fragmentos extraídos de vídeos. Tanto os textos como os vídeos tiveram como função fornecer referências intelectuais e poéticas que pudessem enriquecer a moldura do seminário: "seres ficcionais: identidade e alteridade". De qualquer forma, o percurso seguido privilegiou uma relação entre prática e elaboração dessa prática, em que a segunda deveria sempre seguir a primeira, e não antecipá-la.

No último encontro, o material cênico produzido pelos grupos foi organizado, e desse modo, algumas perguntas que haviam sido levantadas durante o seminário, associadas a algumas ações vocais, funcionaram como elementos de transição entre as cenas. A relação entre as ações vocais, descritas abaixo entre parênteses, e as perguntas, foi definida como segue:

- (Flutuar): Como você sabe se está vivendo uma experiência ou não?

- (Furar): Qual a relação entre um princípio e uma técnica?

- (Escorregar): Como fazer de alguma coisa um material?

- (Rasgar): Se não existem técnicas universalizantes, como inventar técnicas a partir da exploração dos materiais?

- (Amassar): Qual a distância que existe entre eu e o meu material?

- (Gotejar): Como lidar com o outro que não está fora de mim?

- (Derreter): Identidade... Alteridade ... 2 ... Palavrões!

- (Acariciar): Informo? Demonstro? Penso ... penso o que não falo... Falo o que não sinto ... Sinto o que não penso ... Experiencio!

A inserção de tais transições, mais do que buscar fornecer uma unidade ao todo, funcionou como um elemento de resgate de qualidades produzidas durante os encontros.

Tentar descrever a importância desses encontros representa um esforço árduo, pois as palavras escritas aqui não poderão materializar as impressões, as surpresas, o não-dito que deles emergiu. Dentre as surpresas significativas, fui tocado, dentre outras coisas, pela relatividade do tempo. Esses encontros me fizeram perceber, de maneira palpável, que o tempo 'real' é o 


\section{Urdimento}

tempo da experiência, e que portanto poucas horas de relógio podem produzir momentos de qualidade, materiais 'pregnantes', que se trabalhados, podem fazer emanar centelhas potentes, capazes de nos remapear cognitivamente.

\section{Referências bibliográficas}

BENJAMIn, Walter. Magia e Técnica, Arte e Política: ensaios sobre literatura e história da cultura. São Paulo: Brasiliense, 1994.

BONDÍA, Jorge Larossa. Notas Sobre a Experiência e o Saber de Experiência, em Revista Brasileira de Educação, n. 19, pp. 20-28, Jan/Fev/Mar/Abr 2002. Disponível em http://www.anped.org.br/rbe/rbedigital/RBDE19/ RBDE19_04_JORGE_LARROSA_BONDIA.pdf

BONFITTO, Matteo. O Ator Compositor. As ações físicas como eixo: de Stanislávski a Barba. São Paulo: Perspectiva, 2002.

A Cinética do Invisível. Processos de Atuação no Teatro de Peter Brook. São Paulo: Perspectiva, 2009.

PAVIS, Patrice. Dicionário de Teatro. São Paulo: Perspectiva, 2007. 